\title{
Pituitary giant spindle cells oncocytoma - case report
}

\author{
Martha Lilia Tena-Suck ${ }^{1}$, Mauricio Martínez ${ }^{2}$, I saac Jair Palacios-Ortiz ${ }^{2}$, Alma Ortiz Plata ${ }^{3}$, Alma \\ Delia Hernandez ${ }^{4}$
}

1. Department of Neuropathology, National institute of Neurology and Neurosurgery, México City, México. 2. Service of Neurosurgery, National institute of Neurology and Neurosurgery, México City, México. 3. Laboratory of Experimental Neuropathology, National institute of Neurology and Neurosurgery, México City, México. 4. Laboratory of Pathology, National Institute of Rehabilitación, México City, México.

Correspondence: Martha Lilia Tena-Suck. Address: Department of Neuropathology, National institute of Neurology and Neurosurgery, Av Insurgentes Sur 3788 Col. La Fama, Tlalpan C.P. México. E-mail: mltenasuck@gmail.com

Received: February 11, 2015

DOI : $10.5430 / c r c p . v 2 n 3 p 48$
Accepted: March 26, 2015

Online Published: April 9, 2015

\section{Abstract}

Pituitary spindle cell oncocytoma (SCO) is a non-endocrine neoplasm originating in adenohipophysis. It arises from the follicle-stellate cells, and only 17 cases have been published. We reported a rare case of giant SCO in a 59-year-old male who presented with clinical features of hypopituitarism. MRI findings revealed a giant pituitary adenoma. Histologically, tumor formed by homogeneous spindle cells, the tumor cells were immunoreactive to vimentin, FSH, PTTG-1 gene, TTF-1, Fit-1 and Pit-1. In addition, the spindle cells were positive to nestin, vimentin and $\beta$-FGF and low Ki67 labeling index. The electro microscopic image reveled numerous and tortuous mitochondria's and diagnosis of giant spindle cell oncocytoma was given. Conclusion: Histological, immunohistochemical and ultrastructure findings confirmed the diagnosis of spindle cell oncocytoma. In our knowledge, this is the 18th case of its kind in the literature and the first with giant tumor. The biologic characterization of pituitary stem/progenitor and oncocytic cells could also allow a better understanding of the biological basis of some pituitary adenomas and the origin of this tumor.

\section{Key words}

Pituitary, Giant spindle cells oncocytoma, Biology behavior

\section{I ntroduction}

Pituitary adenomas (PA) are clinically symptomatic intracranial tumors and account for approximately $12 \%{ }^{[1]}$. Clinically, the tumors produce variable symptoms depending on the accompanied hormonal dysfunction in addition to the visual field defects as a result of compressing the optic chiasm or optic nerve ${ }^{[1]}$. Based on the size of the tumor, pituitary adenomas are classified into two categories; microadenomas (less than $1 \mathrm{~cm}$ ) and macroadenomas (equal or greater than $1 \mathrm{~cm}$ ). Spindle cell oncocytoma ( $\mathrm{SCO}$ ) of pituitary gland is a rare subtype of pituitary adenoma, it is a relatively recent entity, and is considered as a benign tumors grade I according $\mathrm{WHO}^{[1]}$. SCO is a slowly growing tumor and the clinical and radiological features are nonspecific ${ }^{[2,3]}$ and is often misdiagnosed as pituitary adenoma. Histologically, it consists in irregular spindle cells with abundant eosinophilic and granularly cytoplasm forming fascicles with fewer or no mitotic figures and necrosis have been seen. Tumor cells are usually immunoreactive for S-100 protein, galectin-3, vimentin and epithelial membrane antigen (EMA) and while negative for GFAP, high molecular weight cytokeratin CK (AE1/AE3), smooth muscle actin, desmin, CD34 and CD68, chromogranin, synaptophysin and pituitary hormones (prolactin, growth hormone, TSH, 
ACTH, FSH, LH). The MIB1 (ki67) labeling index is often lower than $10 \%{ }^{[3-6]}$. Ultra structurally, the SCO tumor cells are rich in mitochondria, which are giant mitochondria with lamellar cristae and destruction of internal matrix that confirm the diagnosis ${ }^{[2-6]}$.

We describe a rare case of spindle cells oncocytoma presented as silent giant pituitary adenoma grade IVe according Hardy-Vezina. Frontal craniotomy was performed.

\section{Clinical case}

A 59 year old male was admitted to our institution by cephalous and visual disturbance and hypopituitarism. MRI revealed a big sellar mass with supra and infrasellar outgrowth (see Figure 1a). The mass showed a contrast enhancing in T1weighted with skull base destruction (see Figure 1b) and it was graded as IV-e classification was diagnosed according Hardy-Vezina. After being diagnosed as nonfunctional (silent) macroadenoma, frontal craniotomy was performed. Due to the marked adherence of the capsule to neurovascular structures, a subcapsular decompression was the best that could be achieved. Grossly, the tumor measured $8 \mathrm{~cm} \times 5 \mathrm{~cm}$, Gris-radishes with gross capsule (see Figure 2a). It was found to be elastic, soft and highly vascular.

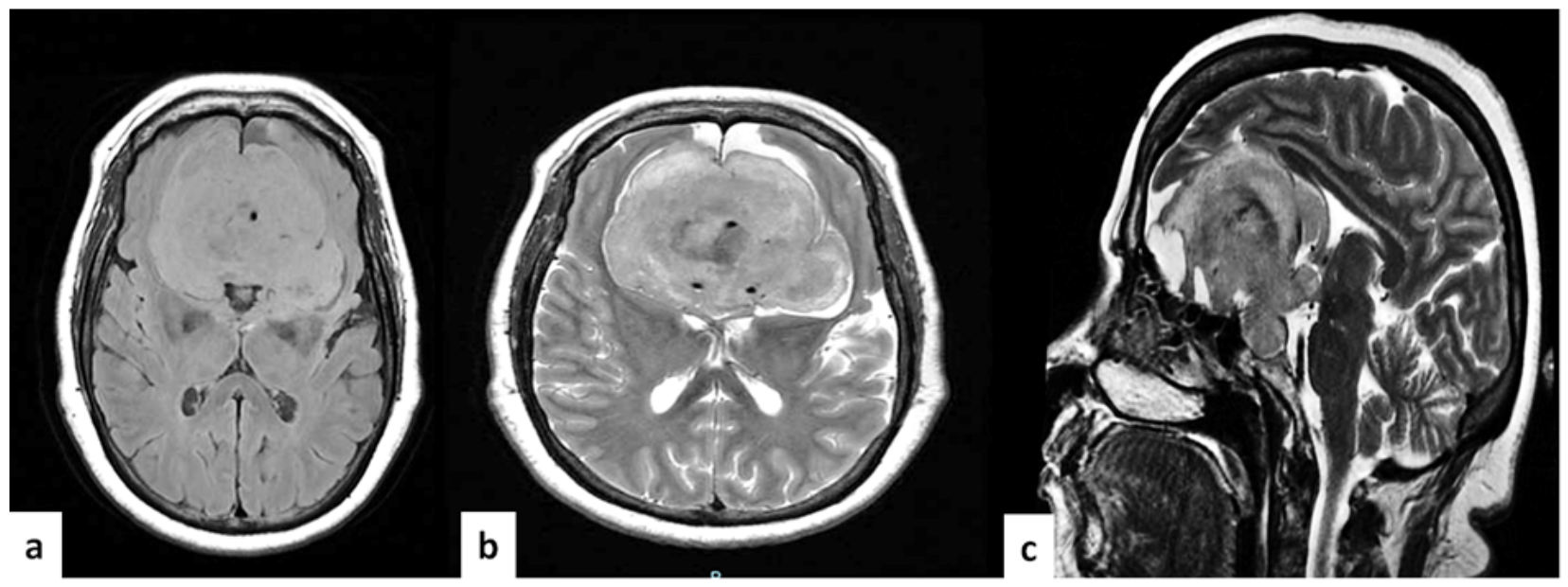

Figure 1. (a) (b) Axial MRI in T1-weighted showed a sellar mass with invasive growth. (c) Sagittal MRI in T2 showing a giant extra-axial mass with displacement of brain parenchymal and hyperintenses areas.

Histopathological examination demonstrated an encapsulated pituitary adenoma with some epithelioid eosinophilic and granular cells (see Figure 2b). Some acini were described with minimal nuclear atypia (see Figure 2c). No mitotic feature was found at the microscopic level. However, necrosis, hemorrhage and hyper vascularity foci were observed (see Figure 2d). Spindle cells were also demonstrated in the capsule (see Figures $2 \mathrm{e}$ and 2f). Ultrastructural imaging illustrated that the spindle cells and other polygonal tumor cells were filed with abundant swollen mitochondria and dispersed small secretory granules in cytoplasm (see Figure $2 \mathrm{~g}$ and $2 \mathrm{~h}$ ). Anterior pituitary hormones tested were negative, but tumor cells were focally immunoreactive for FSH in area of pituitary adenoma and PTTG-1 gene (see Figure 3a), was also positive immunoreaction (see Figure 3b). In addition, the spindle cells were positive for vimentin (see Figure 3c), $\beta$-FGF (see Figure 3d), and nestin was positive in the vessels of both polygonal areas (see Figure 3e) and spindle cells (see Figure 3f). Metalloproteinase 9 was positive in the stromal cells (see Figure 3g). Thyroid transcription factor 1 antigen (see Figure 3h) and Pit-1 (see Figure 3i) and MIB-1(ki67) labeling index was 5\% (see Figure 3j). Few positive cells to Sox2, CD15, and CD133 were observed, whereas Desmin, GFAP, S-100 protein, neurofilament, cytokeratins and synaptophysin were negative in both cell types. Finding, the diagnosis of giant spindle cell oncocytoma (SCO) was given, also named as oncocytoma with epithelial mesenchymal transition (EMT) differentiation. Postoperatively, the patient developed pan hypopituitarism and the patient was put on hormonal substitution. 

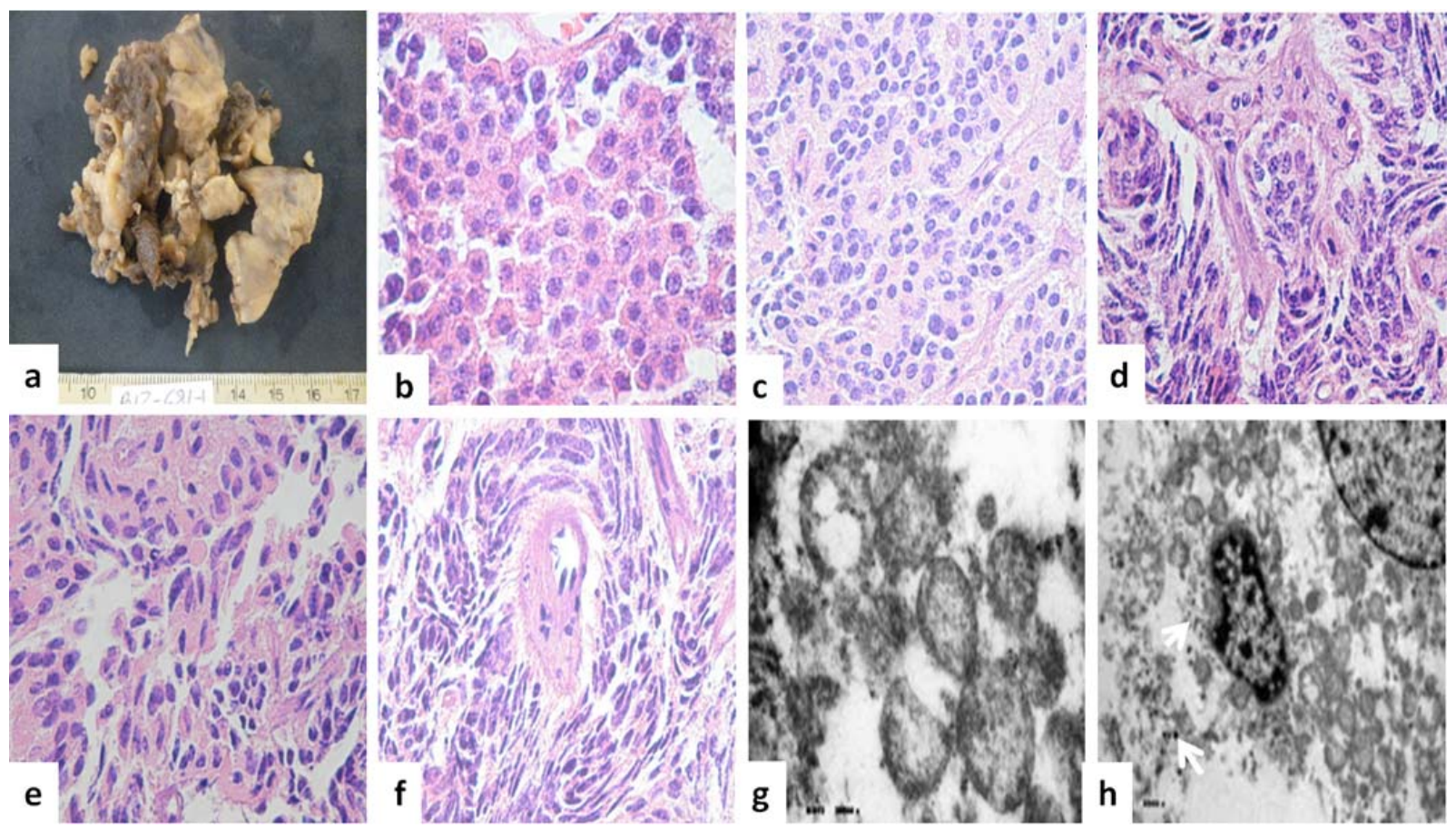

Figure 2. (a) Gross aspect of the tumor resected. Histologically (b and c), tumor cells were spindled and epithelioid and well organized. (d), (e) and (f) observed a solid spindle cell neoplasm with increased cellularity. (e) The tumor cells showed eosinophilic and oncocytic cytoplasm with focal nuclear atypia and pleomorphism. (f) Spindle cell with eosinophilic cytoplasm that formed fascicles (original magnification, $\times 400$; hematoxylin and eosin stain). (g) Electron microscopy simples noted numerous giant mitochondria and in (h) small and few secretory granules were observed (arrows) $(1,394 \mathrm{kd})$.
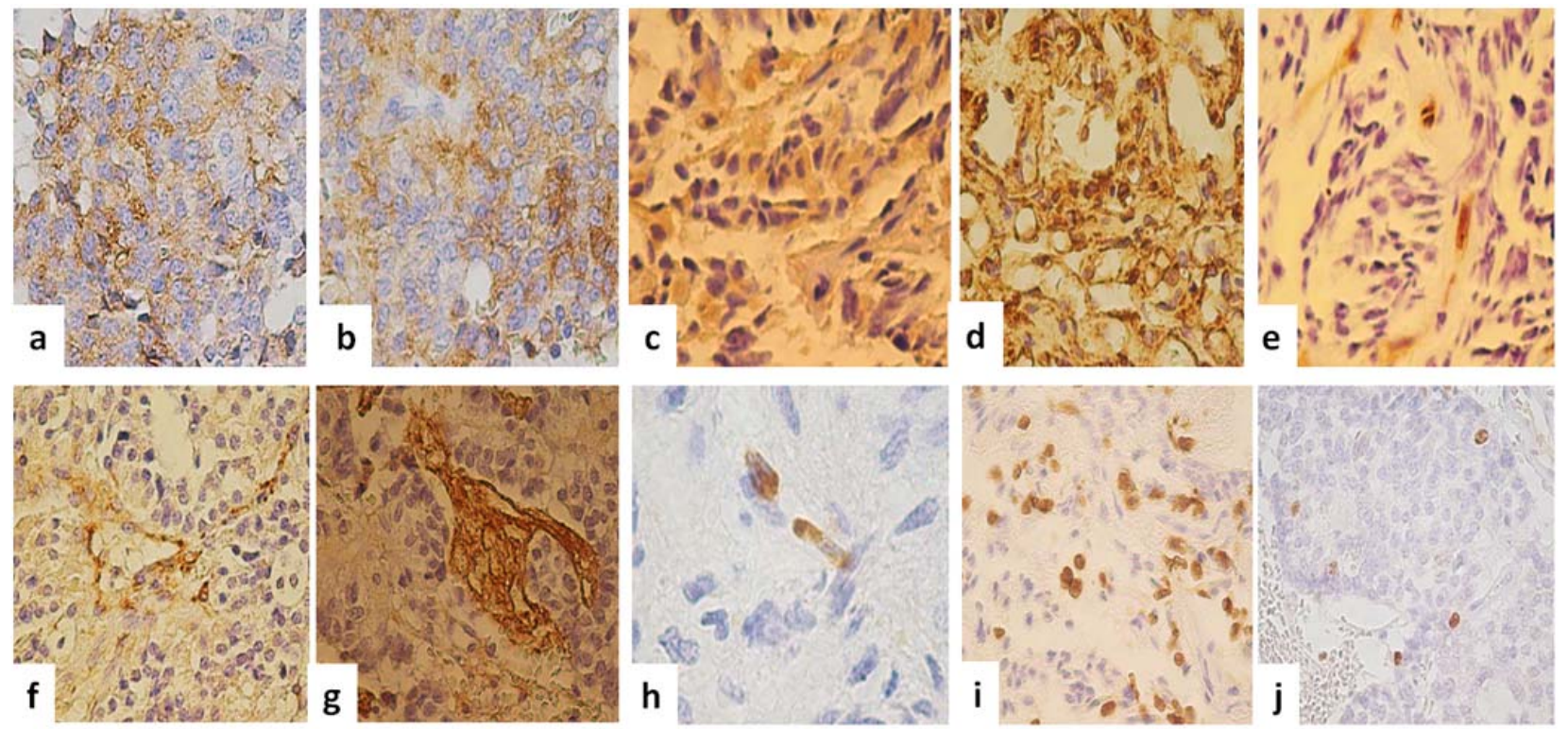

Figure 3. Immunohistochemistry. (a) FSH positive immunoreaction in polygonal cells and in (b) PTTG-1 gen immunoexpression. (c) The spindle cells were positive to vimentin and in (d) $\beta$ - FGF positive immunoexpression. In (e) nestin vessels positive reaction and positive polygonal cells areas were observed, in (f) observed that the spindle cells were also nestin positive immunoreaction. (g) Metalloproteinase 9 was positive in the stroma. In (h) observed nuclear positive expression of thyroid transcription factor 1 and in (i) observed Pit-1 nuclear positive immunoexpression and also in (j) ki-67 nuclear positive immunoreaction (IHQ stain $\times 400$ ). 


\section{Discussion}

SCO is a rare neoplasm of anterior pituitary gland ${ }^{[1,2]}$. It was described by Roncaroli et al. in $2002^{[7]}$, so far no more than 20 cases have been reported, of which only 8 of them had a benign clinical course and six experienced recurrence in spite of comprehensive replacement therapy ${ }^{[1,2]}$. Histogenesis and prognosis of SCO remain uncertain, because most of them have uncertain clinical behavior and need to be documented ${ }^{[2-7]}$. Spindle cell oncocytoma is a tumor of adulthood, the published patient ages ranged from 71 to 53 years (mean 61.6 years) ${ }^{[1]}$. The tumor is giant and invasive pituitary tumor and is considered as one of the most complex neurosurgical challenges ${ }^{[8]}$. Our case was 59 year old male with a radiological enhanced mass of the sellar region, grade IVe according Hardy-Vasinia grade and Knosp grade IV. In the literature, the radiological findings are found to be nonspecific and impossible to be distinguished from other pituitary tumors. It is generally regarded as pituitary tumor. Management of this tumor remains controversial, because few cases have been reported ${ }^{[1,2]}$. Transcranial extensive surgery is recommended, however some tumors described resection through trans-sphenoidal surgery according to the tumor consistency and size. Most management complications are due to the difficulty of surgical resection which needs skill and it is not always possible in the sellar region ${ }^{[8]}$. In our case a wide surgery was performed because of its big size thereof. Despite this massive surgery, recurrences and recurrent bleeding was noted. Regarding the tumor outcome, histologically SCO is a benign tumor. Nevertheless, tumor size is an important factor that should be considered as a poor prognosis. Survival rate is also controversial, nor is well known; the mean time between the surgery and recurrence has been reported to be about 3.3 years (ranging from 5 months to 13 years) and $85.7 \%$ of cases that recurred have been reported in patients underwent incomplete resection at the original surgery ${ }^{[2-6]}$. Incomplete resection of the tumor has been reported to be a significant risk factor for recurrence ${ }^{[1]}$.

Histological, immunohistochemical and structural findings lead to postulate a possible derivation from follicle stellate cells. Very little is known about these cells ${ }^{[2-7,9]}$ and are known to coexpression with GFAP, vimentin, S-100 protein, EMA, and antimitochondrial antibody 113-1 which indicates the presence of mitochondria ${ }^{[7]}$.

Overlapping features of SCO with Pituicytoma can coexist and is considerate as differential diagnosis. SCO tumors are considered to arise from follicle stellate cells, while Pituicytoma are neoplasms that arise from pituicytes, specialized glia of posterior pituitary ${ }^{[8]}$. Both tumors are characterized by simultaneous positive immunoexpression of S-100 protein, vimentin and PGAF. While Pituicytoma also express olig2, IDH1-R132H, NF, galectin-3, cromogranin-A, CD56, EMA, CAM5.2, CD68, TTF- ${ }^{[10]}$, and bcl-2, and ultra-structurally have been identified five variants: light, dark, granular, ependymal, and oncocytic subtype ${ }^{[6,8]}$.

Pituitary tumor-transforming gene 1 (PTTG-1), is a securin, plays an important key role in cell-cycle regulation in pituitary tumors and may thereby results in chromosome dysfunction that may portray a new therapeutic target for malignant tumors ${ }^{[11-13]}$. PTTG1 oncogene promotes tumor malignancy via EMT ${ }^{[11]}$, the fact that our case was positive for PPTG-1 confirmed pituitary origin ${ }^{[14]}$.

\section{Conclusion}

We described a rare case of SCO in an adult, 59-year-old, man whose MRI documented a giant sellar region. Histopathological examination showed a tumor formed predominantly of spindle cells. Immunohistochemical showed positivity for vimentin, S100, EMA, Cytokeratin (CK) (AE1/AE3), glial fibrillary acidic protein (GFAP), and $\beta$ FGF. The diagnosis was confirmed by electron microscopy as Spindle Cell Oncocytoma. This case was considered to be the first case with giant intrasellar mass that expressed stem cells marker and EMT focus or differentiation or promote.

\section{References}

[1] Lloyd RV, Kovacs K, Young WF Jr, et al. Tumours of the pituitary, in WHO Classification of Tumours-Tumours of Endocrine Organs. R. A. DeLellis, R. V. Lloyd, P. U. Heitz, et al. Eds. Lyon, France: IARC Press; 2004. 11-12p. 
[2] Fuller GN, Scheithauer BW, Roncaroli F. Spindle cell oncocytoma. In: Louis DN, Ohgaki H, Wiestler OD, Cavenee WK, editors. World Health Organization Classification of Tumours of the Central Nervous System. Lyon: IARC; 2007. 245-246p. PMid: 17428516

[3] Mete O, Lopes MB, Asa SL. Spindle Cell Oncocytomas and Granular Cell Tumors of the Pituitary Are Variants of Pituicytoma. Am J Surg Pathol. 2013 Jul 24. PMid: 23887161. http://dx.doi.org/10.1097/PAS.0b013e31829723e7

[4] Dahiya S, Sarkar C, Hedley-Whyte ET, et al. Spindle cell oncocytoma of the adenohypophysis: report of two cases. Acta Neuropathol. 2005; 110: 97-99. PMid: 15973544. http://dx.doi.org/10.1007/s00401-005-1009-5

[5] Covington MF, Chin SS, Osborn AG. Pituicytoma, spindle cell oncocytoma, and granular cell tumor: clarification and meta-analysis of the world literature since 1893. AJNR Am J Neuroradiol. 2011; 32: 2067-72. PMid: 21960498. http://dx.doi.org/10.3174/ajnr.A2717

[6] Alexandrescu S, Brown RE, Tandon N, et al. Neuron precursor features of spindle cell oncocytoma of adenohypophysis. Ann Clin Lab Sci. 2012; 42: 123-9. PMid: 22585606.

[7] Roncaroli F, Scheithauer BW, Cenacchi G, et al. 'Spindle cell oncocytoma' of the adenohypophysis: a tumor of folliculostellate cells? Am J Surg Pathol. 2002; 26: 1048-1055. PMid: 12170092. http://dx.doi.org/10.1097/00000478-200208000-00010

[8] Goel A, Nadkarni T, Muzumdar D, et al. Giant pituitary tumors: a study based on surgical treatment of 118 cases. Surgical Neurology. 2004; 61: 436-445. PMid: 15120215. http://dx.doi.org/10.1016/j.surneu.2003.08.036

[9] Vajtai I, Kappeler A, Sahli R. Folliculo-stellate cells of "true dendritic" type are involved in the inflammatory microenvironment of tumor immunosurveillance of pituitary adenomas. Diagn Pathol. 2007; 2: 20-4. PMid: 17597515. http://dx.doi.org/10.1186/1746-1596-2-20

[10] Kleinschmidt-Demasters BK, Lopes MB. Update on Hypophysitis and TTF-1 Expressing Sellar Region Masses. Brain Pathol. 2013; 23: 495-514. PMid: 23701182. http://dx.doi.org/10.1111/bpa.12068

[11] Zhang E, Liu S, Xu Z, et al. Pituitary tumor-transforming gene 1 (PTTG1) is overexpressed in oral squamous cell carcinoma (OSCC) and promotes migration, invasion and epithelial-mesenchymal transition (EMT) in SCC15 cells. Tumour Biol. 2014 Sep; 35(9): 8801-11. PMid: 24879625. http://dx.doi.org/10.1007/s13277-014-2143-2

[12] Hatcher RJ, Dong J, Liu S, et al. Pttg1/securin is required for the branching morphogenesis of the mammary gland and suppresses mammary tumorigenesis. Proc Natl Acad Sci U S A. 2014 Jan 21; 111(3): 1008-13. http://dx.doi.org/10.1073/pnas.1318124111

[13] Yoon CH, Kim MJ, Lee H, et al. PTTG1 oncogene promotes tumor malignancy via epithelial to mesenchymal transition and expansion of cancer stem cell population. J Biol Chem. 2012; 287: 19516-27. PMid: 22511756. http://dx.doi.org/10.1074/jbc.M111.337428

[14] Nieto MA. The ins and outs of the epithelial to mesenchymal transition in health and disease. Annu Rev Cell Dev Biol. 2011; 27: 347-376. PMid: 21740232. http://dx.doi.org/10.1146/annurev-cellbio-092910-154036 